\title{
A Positive Association Between Foot Posture Index and Medial Compartment Knee Osteoarthritis in Moroccan People
}

\author{
F.E. Abourazzak ${ }^{*}, 1$, N. Kadi ${ }^{1}$, H. Azzouzi ${ }^{1}$, F. Lazrak ${ }^{1}$, A. Najdi ${ }^{2}$, C. Nejjari ${ }^{2}$ and T. Harzy ${ }^{1}$ \\ ${ }^{1}$ Rheumatology Department, Hassan II University Hospital, Fez, Morocco \\ ${ }^{2}$ Laboratory of Epidemiology and Public Health, Faculty of Medicine and Pharmacy, Fez, Morocco
}

\begin{abstract}
Objectives: To compare foot posture in people with and without medial compartment knee osteoarthritis (OA), and to assess association between its abnormalities and medial compartment knee OA.

Methods: We compared the foot posture of patients with clinically and radiographically-confirmed medial compartment knee OA and asymptomatic healthy controls using the foot posture index (FPI), navicular height, and the medial arch.

Results: We included 100 patients and 80 asymptomatic controls. The mean age of patients was $59 \pm 7$ (44-76) years and $48 \pm 9$ (28-60) years in the control $(\mathrm{p}=0.06)$. Patients group have more pronated foot for FPI $(1.50 \pm 2.68 v s 0.72 \pm 2.63$; $\mathrm{p}=0.05)$, more flat foot $(42 \%$ vs $22 \% ; \mathrm{p}=0.03)$, and less pes cavus than the control group $\left(58 \% v_{s} 77 \% ; \mathrm{p}=0.004\right)$. However, there was no significant difference between the groups in the navicular height $(3.90 \pm 0.85 \mathrm{~cm} \mathrm{vs} 4.00 \pm 0.76$ $\mathrm{cm} ; \mathrm{p}=0.41)$.

In multivariate statistical analysis, after adjusting for age and body mass index, pronated foot in FPI $(\mathrm{OR}=1.22,95 \% \mathrm{IC}=$ $[1.06-1.40], \mathrm{p}=0.005)$, and pes cavus $(\mathrm{OR}=0.32,95 \% \mathrm{IC}=[0.11-0.93], \mathrm{p}=0.03)$ had a significant correlation with the knee osteoarthritis.

Conclusion: Pronated foot posture and flat foot are significantly associated with medial compartment knee osteoarthritis.
\end{abstract}

Keywords: Foot posture, foot posture index, knee osteoarthritis, medial arch, medial compartment, navicular height.

\section{BACKGROUND}

Foot posture might change the mechanical alignment, dynamic function and the development of musculoskeletal conditions of the lower limb. Foot orthoses, knee braces, and footwear are non operative treatment for osteoarthritis (OA) reducing the knee adduction moment and the loading on the medial compartment as well [1-9]. So, foot posture assessment is the first requirement to select the patients with medial knee osteoarthritis qualified for the non operative treatment. The foot posture measurements include the foot posture index (FPI) [10], navicular height and the medial arch index. The FPI is a valid clinical tool with a good interitem reliability. It quantifies the degree to which a foot can be considered as being in a pronation, supination or neutral position. The evaluation of the medial arch is made by measuring the Djian-Annonier angle on the radiograph of the foot in side view. It is drawn from the lowest point of the calcaneus, the talar head and sesamoids. It is between 120 and $125^{\circ}$, a lower value indicates a hollow foot (pes cavus) and a higher indicates a flat foot. The measurement of navicular height is a direct anthropometric measure of the distance between the navicular tuberosity and ground with the subject in relaxed calcaneal stance.

\footnotetext{
*Address correspondence to this author at the Rheumatology Department, Hassan II University Hospital, Fez, Morocco; Tel: 002126616018 14; Fax: 002125356127 94; E-mail: f.abourazzak@yahoo.fr
}

Although it is important to know and to understand the foot characteristics in patients with medial knee osteoarthritis, few studies have examined the foot posture in this population. Two interesting studies compared foot posture index (FPI) scores between people with knee OA and controls, and the conclusion assumed that people with medial compartment knee OA have a more pronated foot type in comparison with controls $[11,12]$.

The aim of our study was to evaluate foot characteristics of medial compartment knee OA patients and asymptomatic people in Morocco, and to assess the degree of the association between foot posture and knee $\mathrm{OA}$ in comparison to other population.

\section{PATIENTS AND METHODS}

We designed a case-control study comparing the foot posture in patients with medial knee osteoarthritis with a control group of healthy people.

\section{Patients}

The patient group was defined as any patient who consults for knee pain related to medial knee osteoarthritis diagnosed on X-ray. In patients with bilateral knee OA we studied the most painful side. Each compartment of the knee joint (medial compartment, lateral compartment and patellafemoral compartment) was graded and participants with predominantly medial compartment $\mathrm{OA}$ were included in the 
study. Participants from the OA group were included if they were able to walk independently without any pre-existing neurological or other orthopaedic condition that affected their walking. Patients with a history of trauma of the knee, an inflammatory arthritis or microcrystalline pathology and previous joint injury were excluded from the study.

The control group consisted of healthy people with no clinical knee osteoarthritis selected from general population.

All patients and controls gave their written informed consent before being included in the study.

\section{Methods}

All measures were made by the same examiner. We noted the weight, height and BMI of the two groups. An examination of the knee was performed in the group of patients in search of a genu varus or valgus. The grade of the knee OA was assessed using the Kellgren and Lawrence classification on a radiograph of the knee. For both groups, we measured in the lower limb affected by osteoarthritis the navicular height, the foot posture index (FPI) and the medial arch. The latest approved version of the FPI consists of six items and each item is scored between -2 and +2 [10]. The overall posture of the foot is the sum of the different measures, so a neutral foot corresponds to a score of 0 , a pronated foot corresponds to a positive value and a negative value indicates a supination position. The various items of the foot posture index are the talar head palpation, the supra and infra lateral malleolar curvature, the calcaneal frontal plane position, the bulging in the region of the talonavicular joint, the height and congruence of the medial longitudinal arch and the abduction / adduction of the forefoot on the rear foot. All observations were made with subjects standing on both lower limbs. Assessment of the symptomatic leg (or the most symptomatic leg in a case of bilateral involvement) in OA group and the same leg of each peer control was done.

\section{Statistical Analysis}

A descriptive analysis was performed first; qualitative variables were presented as a proportion and continuous variables as a mean $\pm \mathrm{SD}$ and median.

An univariate analysis was then conducted using t test or non parametric test (Mann-Whitney) to compare means. The Chi2 statistics were used for comparison of proportions.

Backwards-manual selection in binary logistic regression model was used to estimate the association of knee OA with explanatory factors. Factors associated with $p$ value $<20 \%$ in univariate analyses were included in the initial multivariate logistic model. The algorithm used to eliminate variables, for instance: First, factors were eliminated from the binomial logistic regression models based on their significance level. Secondly, main effects of potential confounders were selected for elimination if they did not influence the estimated OR and had a negative influence on the global model-fit. Adjusted odds ratios (ORa) and 95\% confidence intervals (CI) are reported for each determinant.

Statistical analysis was carried out using the SPSS, v18. The level of significance was established for $p$ value $<0.05$.

\section{RESULTS}

\section{Demographic Characteristics}

Two groups participated in the study: a knee OA group and an age-matched and gender-matched healthy control group. The OA group included one hundred patients whose $\mathrm{X}$-ray was positive for the medial compartment OA. The control group included eighty participants. The demographic characteristics of both groups are summarized in Table $\mathbf{1}$. Height and body mass index were similar between the groups ( $\mathrm{p}=0.94$ and $\mathrm{p}=0.45$ respectively).

Table 1. Participant's demographic characteristics.

\begin{tabular}{|c|c|c|c|}
\hline & Patients (n=100) & Control Group (n=80) & p Value \\
\hline \hline Age (years)* & $59.68 \pm 7.64$ & $48.66 \pm 9.30$ & 0.06 \\
\hline Female n (\%) & $79(79 \%)$ & $60(75 \%)$ & 0.52 \\
\hline Weight (Kg)* & $80.12 \pm 9.43$ & $72.66 \pm 8.06$ & 0.08 \\
\hline Height (cm)* & $161.49 \pm 7.31$ & $161.42 \pm 6.24$ & 0.94 \\
\hline $\begin{array}{c}\text { Body mass index } \\
\left(\mathbf{k g} / \mathbf{m}^{2}\right)^{*}\end{array}$ & $30.89 \pm 4.94$ & $28.00 \pm 3.81$ & 0.45 \\
\hline
\end{tabular}

* Values are reported as mean $\pm \mathrm{SD}$

\section{Foot Posture Analysis}

Statistical analysis showed significant differences between the two groups. Patients group have more pronated foot for FPI $(1.50 \pm 2.68 v s 0.72 \pm 2.63 ; \mathrm{p}=0.05)$, more flat foot $(42 \%$ vs $22 \%$; $=0.03)$, and less pes cavus than the control group (58\% vs $77 \%$; $\mathrm{p}=0.004)$. However, there was no significant differences between the groups in the navicular height $(3.90 \pm 0.85 \mathrm{~cm} v s 4.00 \pm 0.76 \mathrm{~cm}$; $\mathrm{p}=0.41)$.

In multivariate statistical analysis, after adjusting for age and body mass index, pronated foot in FPI $(\mathrm{OR}=1.22$, $95 \% \mathrm{IC}=[1.06-1.40], \mathrm{p}=0.005)$, and pes cavus $(\mathrm{OR}=0.32$, $95 \% \mathrm{IC}=[0.11-0.93], \mathrm{p}=0.03)$ had a significant correlation with the knee osteoarthritis (Table 2). Pronated foot was associated with medial knee osteoarthritis, while pes cavus was found to protect patient from knee OA.

Table 2. Multivariate statistical analysis results.

\begin{tabular}{|c|c|c|c|c|}
\hline & Odds Ratio & \multicolumn{2}{|c|}{ Confident Interval (95\%) } & $\boldsymbol{p}$ Value \\
\hline \hline $\begin{array}{c}\text { Foot posture index } \\
\text { (Pronation position) }\end{array}$ & 1.220 & 1.060 & 1.403 & 0.005 \\
\hline $\begin{array}{c}\text { Medial arch index } \\
\text { (pes cavus) }\end{array}$ & 0.329 & 0.116 & 0.931 & 0.036 \\
\hline
\end{tabular}

\section{DISCUSSION}

The results demonstrate an association between foot posture and medial knee osteoarthritis. Several recent studies have discussed the benefits of orthotics in decreasing the knees load, so it seems to be interesting to study the foot characteristics in patients with medial knee OA $[13,14]$. In this study, we investigated foot characteristics of people with medial compartment knee OA using three foot measures: the 
FPI, navicular height and the medial arch index. Significant difference was found between the groups for foot measures. Our data suggest that pronated foot in FPI is associated with medial knee OA, while pes cavus seems to protect patients from medial knee OA. Flatfeet are susceptible to high degrees of pronation [15]. Our findings of positive association between medial knee $\mathrm{OA}$ and foot posture index are in agreement with several studies $[11,16]$. Reilly et al. assessed the foot type of three groups of 60 people; the first one with medial compartment knee osteoarthritis, the second with hip osteoarthritis, and the third one with healthy agematched controls [16]. This study showed significant difference between groups concerning ankle dorsiflexion and arches. They concluded that people with medial compartment knee $\mathrm{OA}$ had a normal ankle dorsiflexion and more pronated foot type as indicated by the FPI, while limited range of dorsiflextion and high arches were noted in the hip OA group, and significant difference was found between these two groups compared to controls [16]. However, we found no significant difference in navicular height between the groups, which is also in agreement with Reilly and colleagues. A study of U.S. Marine recruits found that flat or pronated feet were found to be associated with shin splints or knee pain [17]. It has been suggested that high-arched feet are inflexible [18], while flatfeet are more mobile and susceptible to high degrees of pronation $[15,19]$. Persisting subtalar pronation through midstance while the contralateral pelvic advancement is producing an external rotation on the femur contributes to placing the knee under high axial torsion [20]. During walking, which submits the knee to repetitive mechanical loads [21], most of the force is exerted through the medial compartment $[22,23]$. Antero-medial OA of the knee has been proposed as a distinct clinical pathologic entity, the common localization of the lesions to the antero-medial quadrant of the joint suggests it is mechanically driven [22]. The antero-medial quadrant of the knee is the contact area when the leg is extended and fully weightbearing during the midstance phase of gait. This coincides with the timing of subtalar overpronation.

Abnormal foot posture was found in another study of people with severe knee medial compartment OA. In this study which compared the FPI scores between 20 people with knee OA and 20 controls, authors reported a significantly higher median score in those with knee OA, indicative of a more pronated foot posture [11]. Levinger and colleagues compared the FPI between 32 knee OA and 28 controls. They don't found any difference in navicular height between the two groups, however pronated foot type was noted in the knee OA group compared to controls [12]. Recently, Gross et al. reported an association between flat foot morphology and knee pain and medial tibio-femoral cartilage damage, which agrees with our findings [24].

It has been suggested that although the positions of the feet are not pathological, they can lead to a change in the attitude of the foot during walking either in internal or external rotation as the foot is respectively in pronation or supination [25-27]. Supination external rotation attitude can reduce the adduction moment taking action on the knee. The knee adduction moment estimate indirectly the internal stresses in the tibio-femoral compartment [28]. A change in the adduction moment indicates a modification of the distribution of the knee joint load. The adduction moment depends on the mechanical alignment of the knee as well as on the reaction force on the floor [29]. The pronation attitude could move the center of pressure laterally and then decrease the adduction moment, so the foot could attempt to decrease the charge on medial compartment.

It is known that a neutral position without internal or external rotation in the relaxed foot attitude characterize the ideal foot posture. The goniometer used to measure the ankle motion is not adapted to assess pronation and supination. However, the measure using calcaneal angle and navicular height with a plumb line has good results and gives more precision about the alignment even though it is consuming more time and requires more competence [16]. The development of the foot posture index (FPI) by Redmond et al. in 2006 provided a clinical diagnosis tool. This index measures the position of the foot in all three planes of space and assesses two anatomical segments [10]. The FPI was explored in a population of healthy grown-up volunteers from 18 to 57 years old and proved its reliability and its abstract validity $[13,14]$. The FPI gives a comprehensive description of foot posture. However, the FPI is not in wide use as well in osteoarthritic patients.

Whether pronated foot posture is a risk factor for, or a consequence of, medial compartment knee OA cannot be determined from cross-sectional studies such as ours. The question is whether the foot anomaly influences the site at which lower limb OA develops, or whether these changes are secondary to $\mathrm{OA}$ and should be considered as compensatory mechanisms. People with medial compartment knee OA often have genu varum malalignment of the knee, which has been shown to increase the risk of development and progression of knee OA. Genu varum malalignment of the knee may lead to compensatory foot pronation to enable the foot to be plantigrade when weightbearing [30]. None of our patients could affirm if the anomaly of its foot posture is acquired or if it is dated in childhood. Due to the potential effect of foot alignment on the loading axis of the lower limb, prospective studies are needed to better understand the contribution of foot structure and function to the development of internal femoro-tibial OA.

These findings could have therapeutic implications in the management of medial compartment knee OA, especially the use of the laterally wedged soles which can act on symptoms by reducing the knee adduction moment [31, 32]. However, laterally wedged insoles can alter foot motion, specifically increasing rearfoot pronation. Accentuation of rearfoot pronation in already pronated feet could potentially result in detrimental changes to lower limb kinematics [12]. But the addition of an arch support to laterally wedged insoles could maintain normal rearfoot motion while also enhancing the ability of the insole to reduce the knee adduction moment. A longitudinal investigation is required to better understand the contribution of orthotic and footwear interventions in the management of medial compartment knee OA.

\section{CONCLUSION}

The foot posture is strongly correlated with the internal femoro-tibial knee OA. In consequent, clinical examination of the feet in patients suffering from knee $\mathrm{OA}$ is primordial 
by using the clinical tools such as FPI, which remains a simple tool of clinical diagnosis. The assessment of foot posture of people with medial compartment OA is necessary in order to improve our understanding of foot orthoses and foot wear modification on lower limbs alignment and function.

\section{CONFLICT OF INTEREST}

The authors confirm that this article content has no conflict of interest.

\section{ACKNOWLEDGEMENTS}

Declared none.

\section{REFERENCES}

[1] Erhart JC, Mundermann A, Elspas B, Giori NJ, Andriacchi TP. A variable-stiffness shoe lowers the knee adduction moment in subjects with symptoms of medial compartment knee osteoarthritis. J Biomech 2008; 41: 2720-5.

[2] Shakoor N, Lidtke RH, Sengupta M, Fogg LF, Block JA. Effects of specialized footwear on joint loads in osteoarthritis of the knee. Arthritis Rheum 2008; 59: 1214-20.

[3] Crenshaw SJ, Pollo FE, Calton EF. Effects of lateral-wedged insoles on kinetic sat the knee. Clin Orthop Relat Res 2000; 375: 185-92.

[4] Shimada S, Kobayashi S, Wada M, et al. Effects of disease severity on response to lateral wedged shoe insole for medial compartment knee osteoarthritis. Arch Phys Med Rehabil 2006; 87: 1436-41.

[5] Nakajima K, Kakihana W, Nakagawa T, et al. Addition of an arch support improves the biomechanical effect of a laterally wedged insole. Gait Posture 2009; 29: 208-13.

[6] Baker K, Goggins J, Xie H, et al. A randomized crossover trial of a wedged insole for treatment of knee osteoarthritis. Arthritis Rheum 2007; 56: 1198-203

[7] Shelburne KB, Torry MR, Steadman JR, Pandy MG. Effects of foot orthoses and valgus bracing on the knee adduction moment and medial joint load during gait. Clin Biomech 2008; 23: 814-21.

[8] Hinman RS, Bowles KA, Payne C, Bennell KL. Effect of length on laterally wedged insoles in knee osteoarthritis. Arthritis Rheum 2008; 59: 144-7.

[9] Hinman RS, Payne C, Metcalf BR, Wrigley TV, Bennell KL. Lateral wedges in knee osteoarthritis: What are their immediate clinical and biomechanical effects and can these predict a threemonth clinical outcome? Arthritis Rheum 2008; 59: 408-15.

[10] Redmond AC, Crosbie J, Ouvrier RA. Development and validation of a novel rating system for scoring standing foot posture: the Foot Posture Index. Clin Biomech 2006; 21: 89-98.

[11] Reilly K, Barker K, Shamley D, Newman M, Oskrochi GR, Sandall $\mathrm{S}$. The role of foot and ankle assessment of patients with lower limb osteoarthritis. Physiotherapy 2009; 95: 164-9.

[12] Levinger P, Menz HB, Fotoohabadi MR, Feller JA, Bartlett JR, Bergman NR. Foot posture in people with medial compartment knee osteoarthritis. J Foot Ankle Res 2010; 3: 29.
[13] Keenan A, Redmond A, Horton M, Conaghan P, Tennant A. The foot posture index: Rasch analysis of a novel, foot specific outcome measure. Arch Phys Med Rehabil 2007; 88: 88-93.

[14] Noakes H, Payne C. The reliability of the manual supination resistance test. J Am Podiatr Med Assoc 2003; 93: 185-9.

[15] Mann RA, Hagy J. Biomechanics of walking, running and sprinting. Am J Sports Med 1981; 8: 345-50.

[16] Reilly K, Barker K, Shamley D, Sandall S. Influence of foot characteristics on the site of lower limb osteoarthritis. Foot Ankle Int 2006; 27: 206-11.

[17] Kaufman KR, Brodine SK, Shaffer RA, Johnson CW, Cullison TR. The effect of foot structure and range of motion on musculoskeletal overuse injuries. Am J Sports Med 1999; 27: 585-93.

[18] Giladi M, Milgrom C, Stein M, Danon Y. The low arch, a protective factor in stress fractures. A prospective study of 295 military recruits. Orthop Rev 1985; 14: 709-12.

[19] Subotnick SI. Biomechanics of the subtalar and midtarsal joints. J Am Podiatr Assoc 1985; 65: 756-64

[20] Tiberio D. The effect of excessive subtalar joint pronation on patellofemoral mechanics: A theoretical model. JOSPT 1987; 9: 160-5.

[21] Schipplein AD, Andriacchi TP. Interaction between active and passive knee stabilizers during level walking. J Orthop Res 1991; 9: 113-9.

[22] Goodfellow J, O'Connor J. The mechanics of the knee and prosthesis design. J Bone Joint Surg 1978; 60: 358-69.

[23] White SH, Ludkowski PF, Goodfellow JW. Anteromedial osteoarthritis of the knee. J Bone Joint Surg 1991; 73: 582-6.

[24] Gross KD1, Felson DT, Niu J, et al. Flat Feet Are Associated With Knee Pain and Cartilage Damage in Older Adults. Arthritis Care Res 2011; 63: 937-44.

[25] Guichet J-M, Javed A, Russell J, Sahel M. Effect of the foot on the mechanical alignment of the lower limbs. Clin Orthop Relat Res 2003; 145: 193-201.

[26] Teichtahl A, Morris M, Wluka A, Bach T, Cicuttini F. A comparison of gait patterms between the offspring of people with medial tibiofemoreal osteoarthritis and normal controls. Clin Exp Rheumatol 2003; 21: 412-3.

[27] Andrews M, Noyes F, Hewitt T, Andriacchi T. Lower limb alignment and foot angle are related to stance phase adduction in normal subjects: a critical analysis of the reliability of gait analysis data. J Orthop Res 1996; 14: 289-95.

[28] Pollo FE, Otis JC, Backus SI, Warren RF, Wickiewicz TL. Reduction of medial compartment loads with valgus bracing of the osteoarthritic knee. Am J Sports Med 2002; 30: 414-21.

[29] Beaudreuil J, Bendaya S, Faucher M, et al. Recommandations cliniques pratiques pour les orthèses de repos, souples non adhésives et articulées dans la gonarthrose. Rev Rhum 2009; 76 : 1284-92.

[30] Riegger-Krugh C, Keysor JJ. Skeletal malalignment of the lower quarter: correlated and compensatory motions and postures. J Orthop Sports Phys Ther 1996; 23: 164-70.

[31] Kerrigan DC, Lelas JL, Goggins J, Merriman GJ, Kaplan RJ, Felson DT. Effectiveness of a lateral-wedge insole on knee varus torque in patients with knee osteoarthritis. Arch Phys Med Rehabil 2002; 83: 889-93.

[32] Rodrigues PT, Ferreira AF, Pereira RM, Bonfa E, Borba EF, Fuller R. Effectiveness of medial-wedge insole treatment for valgus knee osteoarthritis. Arthritis Rheum 2008; 59: 603-8.

This is an open access article licensed under the terms of the Creative Commons Attribution Non-Commercial License (http://creativecommons.org/licenses/by-nc/ $3.0 /$ ) which permits unrestricted, non-commercial use, distribution and reproduction in any medium, provided the work is properly cited. 